\title{
Reducing gastric cancer through gastritis screening
}

In both sexes together, lung cancer is the most commonly diagnosed cancer $(11.6 \%$ of the total cases) and the leading cause of cancer death (18.4\% of the total cancer deaths), closely followed by female breast cancer $(11.6 \%)$, prostate cancer $(7.1 \%)$, and colorectal cancer $(6.1 \%)$ for incidence; and colorectal cancer $(9.2 \%)$, stomach cancer $(8.2 \%)$, and liver cancer $(8.2 \%)$ for mortality [1].

Gastric cancer incidence rates have been on the decline in most regions of the world but there are still significant geographic, ethnic, and socioeconomic differences in distribution [1]. Several risk factors are thought to be responsible for gastric cancer including salt and smoked food, cigarette smoking, low socioeconomic status, low consumption of fruits and vegetables, use of antioxidants among others [1].

Although several risk factors are described, Helicobacter pylori infection is the main cause. The World Health Organization's International Agency for Research on Cancer (IARC) classified $H$. pylori as a group 1 or definite carcinogen $[2,3]$. In addition, having first-degree relatives diagnosed with gastric cancer is a strong and consistent risk factor for gastric cancer [4]. Emigrants from high-incidence to low-incidence countries often experience a decreased risk of developing gastric carcinoma. Such findings strongly suggest that environmental factors have an important role in the etiology of gastric cancer and that exposure to risk factors occurs early in life [5].

Along with $H$. pylori, lifestyle and environmental factors play a significant role in the development of cancer. Truly hereditary (familial) gastric cancer accounts for $1 \%-3 \%$ of the global burden of gastric cancer and comprises at least three major syndromes: hereditary diffuse gastric cancer, gastric adenocarcinoma and proximal polyposis of the stomach, and familial intestinal gastric cancer [6].

In the stomach, chronic inflammation causes metaplasia and creates a favorable environment for the evolution of gastric cancer. Several previous studies have attempted to elucidate the association of Tumor Necrosis Factor- $\alpha-308$ (TNF- $\alpha-308$ ) $\mathrm{G} / \mathrm{A}$ promoter polymorphism causing inflammation and eventual development of gastric cancer [7]. The paper by Xin Jiang et al. [8] of this issue attempted to carry out a systematic review and meta-analysis through extensive literature search of case control studies. They performed a decent metaanalysis of results to look for the possible association of gene pleomorphism and gastric cancer. The study with pooling of much larger sample did not show any such association. At this point, the study has given evidence that TNF- $\alpha-308 \mathrm{G}>\mathrm{A}$ (GG, GA, AA) pleomorphism is unlikely to have a role in early diagnosis and early treatment of gastric inflammation to prevent gastric cancer. Screening for $H$. pylori and advice for appropriate lifestyle can continue to play a significant role in gastric cancer prevention and early treatment. It is important to identify chronic $H$. pylori-induced gastritis, which may progress through premalignant stages of atrophic gastritis, intestinal metaplasia, and dysplasia, to eventually gastric cancer. This cascade may provide a basis for early detection and treatment of gastric cancer. At present, epidemiology of gastric cancer and premalignant gastric lesions should guide the development of screening and surveillance strategies. Screening for premalignant gastric lesion should serve as distinct approach in countries with low and high gastric cancer incidences [9].

*Correspondence to: Editorial Office of Asian Biomedicine, Faculty of Medicine, Chulalongkorn University, Bangkok 10330, Thailand, e-mail: abmjournal@chula.ac.th

O Open Access. ๑ 2020 Editorial Office of Asian Biomedicine, published by Sciendo. (๔) BY-NC-ND This work is licensed under the Creative Commons Attribution NonCommercial-NoDerivatives 4.0 License. 


\section{References}

[1] Bray F, Ferlay J, Soerjomataram I, Siegel RL, Torre LA, Jemal A. Global cancer statistics 2018: GLOBOCAN estimates of incidence and mortality worldwide for 36 cancers in 185 countries. CA Cancer J Clin. 2018; 68:394-424.

[2] IARC Working Group on the Evaluation of Carcinogenic Risks to Humans, Schistosomes, Liver Flukes and Helicobacter pylori. Vol 61 of IARC monographs on the evaluation of carcinogenic risks to humans. International Agency for Research on Cancer, Lyon; 1994.

[3] Karimi P, Islami F, Anandasabapathy S, Freedman ND, Kamangar F. Gastric cancer: descriptive epidemiology, risk factors, screening, and prevention. Cancer Epidemiol Biomarkers Prev. 2014; 23:700-13.

[4] Choi YJ, Kim N. Gastric cancer and family history. Korean J Intern Med. 2016; 31:1042-53.
[5] Hanley AJ, Choi BC, Holowaty EJ. Cancer mortality among Chinese migrants: a review. Int J Epidemiol. 1995; 24:255-65.

[6] Oliveira C, Pinheiro H, Figueiredo J, Seruca R, Carneiro F. Familial gastric cancer: genetic susceptibility, pathology, and implications for management. Lancet Oncol. 2015; 16:e60-70.

[7] Bhayal AC, Krishnaveni D, RangaRao KP, Bogadi V, Suman C, Jyothy A, et al. Role of tumor necrosis factor- $\alpha-308$ G/A promoter polymorphism in gastric cancer. Saudi J Gastroenterol. 2013; 19:182-6.

[8] Jiang X, Naikoo NA, Gao S. Meta-analysis of tumor necrosis factor- $\alpha-308 \mathrm{G}>\mathrm{A}$ polymorphism in gastric cancer. Asian Biomed (Research Review News). 2020; 14:91-6.

[9] de Vries AC, Kuipers EJ. Epidemiology of premalignant gastric lesions: implications for the development of screening and surveillance strategies. Helicobacter. 2007; 12(Suppl 2):22-31. 